\title{
UNDERSTANDING NEW ZEALAND ADULTS'ATTITUDES TOWARDS DIGITAL INTERVENTIONS FOR HEALTH
}

\author{
Holly Wilson, \& Liesje Donkin \\ Department of Psychological Medicine, University of Auckland (New Zealand)
}

\begin{abstract}
E-health has transformed healthcare by improving access and reach of health services, which is now more critical than ever given the COVID-19 pandemic. One aspect of e-health is the delivery of health interventions via the internet or through smartphone apps, known as digital interventions (DI). These DI can improve physical and mental health for people, by modifying behaviour and improving illness management. Despite, the benefits of DI use remains low. One explanation for this low usage is people's attitudes towards DI. Indeed, having a positive attitude towards DI is associated with an increased likelihood of wanting to engage with DI. Therefore, people's attitudes towards digital interventions are important in understanding if people are willing to engage with them. To date, limited research exists about attitudes and much of this varies based on region and population. Along, with understanding people's attitudes it is important to understand what shapes people's attitudes towards these interventions. Therefore, this study sought to determine New Zealand (NZ) adults' attitudes towards DI and what shapes these attitudes. In order to address these questions a cross-sectional survey was used. Results indicate that NZ adults have neutral to somewhat positive attitudes to DI and their attitudes are influenced by common factors including: beliefs about accessibility of DI and the COVID-19 experience. These findings suggest that some NZ adults have a positive attitudes to DI, but overall people's attitudes needed to be addressed to ensure people are ready to use DI.
\end{abstract}

Keywords: Digital interventions, attitudes, e-health, telehealth.

\section{Introduction}

E-health has transformed healthcare, by making healthcare safer and more accessible (Eden, Burton-Jones, Scott, Staib, \& Sullivan, 2018; Keasberry, Scott, Sullivan, Staib, \& Ashby, 2017). Moreover, healthcare has been transformed dramatically due to the COVID-19 pandemic (Hassounah, Raheel, \& Alhefzi, 2020) as healthcare delivery needed to rapidly shift to minimal face-to-face contact in a situation of unprecedented demand on resources. Thus bringing e-health to the forefront of healthcare (Hassounah et al., 2020; Isautier et al., 2020; Peine et al., 2020). As such, e-health has become a major tool in the fight against COVID-19.

One component of e-health is delivering health interventions via smartphone or internet, termed digital interventions (DI). DI transform people's health by preventing the development of disease (Oosterveen, Tzelepis, Ashton, \& Hutchesson, 2017) and supporting the management (Parks et al., 2020) of health conditions. Such improvements in health are achieved by several mechanisms, including promotion of healthy behaviours (Oosterveen et al., 2017) and improving people's mental wellbeing (Linardon, Cuijpers, Carlbring, Messer, \& Fuller-Tyszkiwwicz, 2019). What is more, DI have been utilised in the fight against COVID-19 (Hassounah et al., 2020). For instance, Saudi Arabi has used DI throughout the pandemic to support people who were distressed (Hassounah et al., 2020). The potential of DI during COVID-19 is endless, with DI having the potential to keep people healthy, reduce the demand on already strained health recourses and help manage people's distress. Given this, it is clear that DI are now more important than ever yet people's actual use of DI is poor (Baumel, Muench, Edan, \& Kane, 2019; Fleming et al., 2018).

Poor attitudes to DI are one explanation for this poor usage. Attitudes are an individual's complete appraisal of the situation or thing (Fishbein \& Ajzen, 1975). Positive attitudes are associated with an increased likelihood of behaviour and behavioural intentions (Davis, 1989; Fishbein \& Ajzen, 1975; McEachan, Conner, Taylor, \& Lawton, 2011; Rosenstock, Strecher, \& Becker, 1988). Such as in the case of DI, people with more favourable attitudes to DI are more likely to have positive intentions to use DI, and 
this is supported by research (Askari, 2020; Patel et al., 2020; Wangberg, Gammon, \& Spitznogle, 2007). Therefore, people's attitudes are crucial to understanding people's readiness to engage with DI.

To date, little is known about people's attitudes to DI as research has found substantial variation in people's attitudes to DI (Baumeister et al., 2015; March et al., 2018; Proudfoot et al., 2010). Moreover, there is substantial variation across countries; for instance, people in Iran have more positive attitudes to DI compared to people in Australia (Clough, Zarean, et al., 2019).

It is also essential to consider what shapes these attitudes to DI to provide insight into how people come to have these attitudes and potential avenues of modification. Several factors shape people's attitudes to DI including knowledge (Mayer et al., 2019), confidence using DI (Davis, 1989, 1993) and perceptions of accessibility (Patel et al., 2020).

To date, no studies have examined NZ adults' attitudes to DI. This gap is surprising, given COVID-19 and the NZ government is incorporating e-health technologies into healthcare delivery (Ministry of Health, 2016). So, the NZ government is likely to utilise DI, but it is unclear what NZ adults think about DI. Therefore, this study sought to understand NZ adults' attitudes to DI. Overall, there are two main purposes of this study: 1) to understand NZ adults' attitudes to DI and 2) what shapes these attitudes. In order to answer these questions, a cross sectional survey was conducted with NZ adults.

\section{Method}

A cross-sectional survey of NZ adults was conducted. Several recruitment methods were used, both online and offline, aiming to gain a representative sample.

\subsection{Ethics approval} Committee.

Ethical approval was granted by The University of Auckland Human Participants Ethics

\subsection{Study sample}

An ideal sample size of 400 was determined with the aim of gaining a representative sample of NZ adults. Participants were NZ citizens or residents over the age of 18. Data collection began in October 2020 and is still ongoing.

\subsection{Survey procedure}

The survey was completed either online or by paper and pen. The first section collected basic demographic, internet access, and health information. Questions for this section were drawn from the NZ census, previous research and in some instances were generated by the researchers. The second section collected information on people's attitudes about DI. This section determined people's exposure to DI and their current attitudes to DI. People's attitudes were measured on a series of items, drawn from previous studies (Clough, Eigeland, Madden, Rowland, \& Casey, 2019; Ebert et al., 2015; Lin, Faust, Ebert, Krämer, \& Baumeister, 2018; Schröder et al., 2015) and some generated by the researchers. For each item participants responded on either a 5- or 7-point Likert scale consistent with the original format of the questions. The final section, examined what shaped people's attitudes to DI. This section examined the role of factors by using items drawn from previous studies (Clough, Eigeland, et al., 2019; Ebert et al., 2015; Lin et al., 2018; Liu et al., 2015; Schröder et al., 2015) and some generated by researchers. For each item people responded on 5-point Likert scales.

\subsection{Data analysis}

Data analysis used SPSS version 26. Data was cleaned, by removing participants $(9 \% \mathrm{n}=22)$ who did not reach the cut-off point of $29 \%$ completion Data was then analysed by looking at descriptive statistics and frequencies of each item. Persons correlation analysis was used to understand how factors influenced people's attitudes.

\section{Results}

\subsection{Sample}

This preliminary analysis includes 230 participants who ranged in age from $18-86, M d n=44.00$, $M=44.08, S D=17.40$. Twenty-one percent identified as male, $76 \%$ as female and $<1 \%$ ( 1 person each) as gender-neutral and nonbinary; $88 \%$ were NZ citizens, and $12 \%$ were residents, all living in NZ. The majority (99\%) of participants had access to the internet at home were frequent users of the internet with $78 \%$ using the internet five or more times daily and $70 \%$ spending more than 60 minutes on the internet daily. In addition, $96 \%$ had an internet-capable phone, $3 \%$ did not and $<1 \%$ were unsure. 


\subsection{NZ adult's attitudes to DI}

In order to determine people's attitudes, each item was examined individually to indicate people's attitudes. As seen in Figure 1., NZ adults had neutral to somewhat positive attitudes to DI for mental and physical health. The majority of NZ adults reported neutral attitudes to each item, with more people being positive than negative views, indicating that $\mathrm{NZ}$ adults have somewhat positive attitudes to DI.

\subsection{How factors shape people's attitudes toward DI}

To examined the effect of factors supported by the literature on people's attitudes Pearson's correlations were conducted. As seen in table 1, several factors were significantly correlated with people's attitudes. Specifically, having greater knowledge, higher confidence using and higher perceived value of the accessibility of DI were associated with weak to moderate positive or negative correlations with people's attitudes. Also, people's experience with COVID-19 influenced their attitudes to DI. More specifically, $41 \%$ of participants reported that were more likely to use a DI as a result of COVID- 19 and $5 \%$ less likely to use DI. Fifty-four per cent reporting no change in intentions to use DI, due to their experience of COVID-19.

\section{Discussion}

The purpose of this study was to understand NZ adults' attitudes to DI and what shapes these attitudes. Based on the findings of this study, NZ adults appear to have neutral to somewhat positive attitudes to DI. Moreover, people's knowledge, confidence, perceptions of accessibility, and experience with COVID-19 have shaped these attitudes to DI. This finding suggest that the people of NZ are somewhat ready to engage with DI, but that there may need to be work to improve people's attitudes towards DI.

This study fits with previous research which shows that peoples' knowledge (Mayer et al., 2019), confidence using DI (Davis, 1989, 1993), perceptions of accessibility (Patel et al., 2020) of DI shape people's attitudes to DI. This study adds to this literature by demonstrating that people's experience with COVID-19 also, shapes people's attitudes to DI. Perhaps, people's experience with COVID has increased their exposure to DI, which results in more positive attitudes to DI.

One limitation of this study is the sample it is not representative of NZ adults. The study sample is predominantly female, highly educated and have internet access, which does not accurately provide a representative sample of NZ adults. Therefore, this study may not actuality reflect NZ adults' attitudes to DI, but rather those that are willing to participate in research.

The findings of this study have important implications. Practically, this study suggests that NZ adults are somewhat ready to engage with DI. These DI could be used in NZ to help aid the fight against COVID-19, with people being somewhat ready to engage with these interventions. In addition, this study highlights key factors that contribute to people's attitudes, which could be used to improve people's attitudes. Future, research could look at the effect of manipulating these factors on people's attitudes. Theoretically, this study further expands the understanding of what shapes people's attitudes by outlining the importance of people's experience with COVID-19.

Overall, this study demonstrates that NZ adults have somewhat positive attitudes to DI, suggesting that NZ adults are somewhat ready to engage with DI. Further, this study outlines that people's knowledge, perception of effectiveness, accessibility, confidence using DI and experience with COVID-19 shape people's attitudes to DI.

Figure 1. Mean attitude score for attitude items. Error bars represent standard deviation.

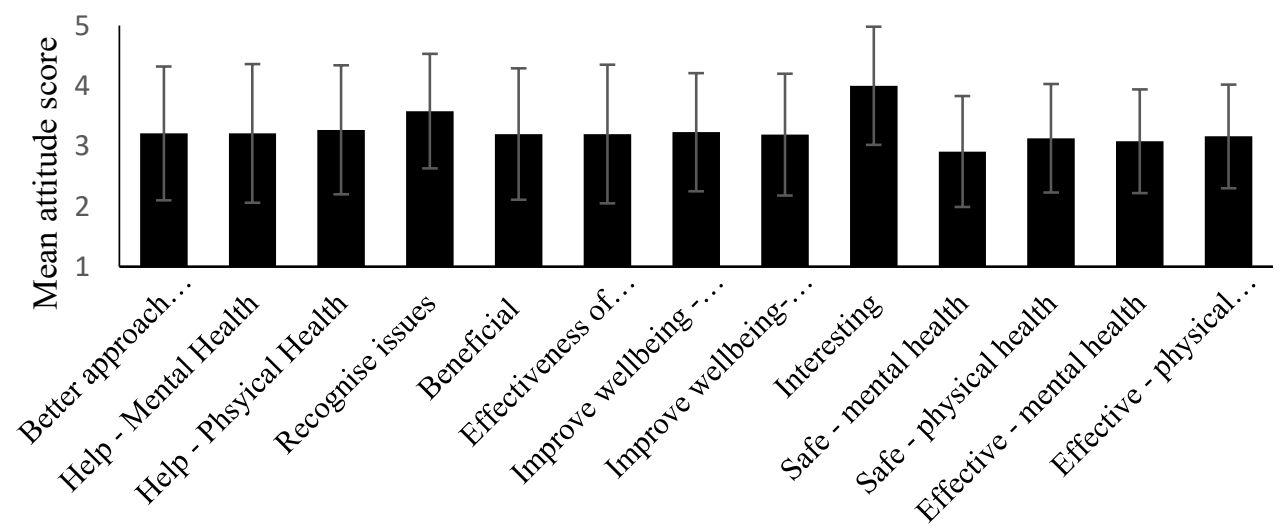


Table 1. Persons correlations between attitude measures and factors which shape these attitudes.

\begin{tabular}{|c|c|c|c|c|c|c|c|c|c|}
\hline \multirow{4}{*}{ Factor } & \multirow[b]{4}{*}{ Item } & \multicolumn{8}{|c|}{ Attitude Measures } \\
\hline & & \multicolumn{4}{|c|}{ Receive help from DI } & \multicolumn{4}{|c|}{ Believe that DI are effective } \\
\hline & & \multicolumn{2}{|c|}{ Mental Health } & \multicolumn{2}{|c|}{ Physical Health } & \multicolumn{2}{|c|}{ Mental Health } & \multicolumn{2}{|c|}{ Physical Health } \\
\hline & & $r$ & $p$ & $r$ & $p$ & $r$ & $p$ & $r$ & $p$ \\
\hline Knowledge & $\begin{array}{l}\text { Mental } \\
\text { Health } \\
\text { Physical } \\
\text { Health }\end{array}$ & $\begin{array}{l}0.283 \\
0.249\end{array}$ & $\begin{array}{l}<.001 \\
<.001\end{array}$ & $\begin{array}{c}0.15 \\
0.327\end{array}$ & $\begin{array}{l}<.05 \\
<.001\end{array}$ & $\begin{array}{l}0.233 \\
0.297\end{array}$ & $\begin{array}{l}<.001 \\
<.001\end{array}$ & $\begin{array}{l}0.183 \\
0.316\end{array}$ & $\begin{array}{l}<.05 \\
<.001\end{array}$ \\
\hline $\begin{array}{l}\text { Internet } \\
\text { Confidence }\end{array}$ & $\begin{array}{l}\text { Find DI easy } \\
\text { to use } \\
\text { Using DI } \\
\text { would be } \\
\text { simple }\end{array}$ & 0.403 & $<.001$ & 0.266 & $<.001$ & 0.407 & $<.001$ & 0.321 & $<.001$ \\
\hline Accessibility & $\begin{array}{l}\text { Complete in } \\
\text { own time } \\
\text { Value the } \\
\text { privacy }\end{array}$ & $\begin{array}{l}0.371 \\
0.371 \\
0.33 \\
\end{array}$ & $\begin{array}{l}<.001 \\
<.001 \\
<.001\end{array}$ & $\begin{array}{l}0.329 \\
0.329 \\
0.352\end{array}$ & $\begin{array}{l}<.001 \\
<.001 \\
<.001\end{array}$ & $\begin{array}{l}0.366 \\
0.366 \\
0.448 \\
\end{array}$ & $\begin{array}{l}<.001 \\
<.001 \\
<.001\end{array}$ & $\begin{array}{l}0.427 \\
0.427 \\
0.484\end{array}$ & $\begin{array}{l}<.001 \\
<.001 \\
<.001\end{array}$ \\
\hline
\end{tabular}

\section{References}

Askari, M., Klaver, N. S, van Gestel, T. J, Klundert, J. V. D. (2020). Intention to use medical apps among older adults in the Netherlands: Cross-sectional study. . Journal of Medical Internet Research, 22, e18080. doi:10.10.2196/18080

Baumeister, H., Seifferth, H., Lin, J., Nowoczin, L., Lüking, M., \& Ebert, D. (2015). Impact of an acceptance facilitating intervention on patients' acceptance of internet-based pain interventions: A randomized controlled trial. The Clinical Journal of Pain, 31, 528 - 535 doi:10.1097/AJP.0000000000000118

Baumel, A., Muench, F., Edan, S., \& Kane, J. M. (2019). Objective user engagement with mental health apps: systematic search and panel-based usage analysis. Journal of Internet Research, 21, e14567. doi:10.21996/14567

Clough, B. A., Eigeland, J. A., Madden, I. R., Rowland, D., \& Casey, L. M. (2019). Development of the eTAP: a brief measure of attitudes and process in e-interentions for mental health. Internet Interventions, 18, 100256. doi:10.1016/j.invent.2019.100256

Clough, B. A., Zarean, M., Ruane, I., Mateo, N. J., Aliyeva, T. A., \& Casey, L. M. (2019). Going global: do consumer preferences, attitudes, and barriers to using e-mental health services differ across countries? Journal of Mental Health, 28, 17-25. doi:10.1080/09638237.2017.1370639

Davis, F. D. (1989). Perceived usefulness, perceived ease of use and user acceptance of information technology. MIS Quarterly, 13, 319 - 339

Davis, F. D. (1993). User acceptance of information technology: system characteristics, user perceptions and behavioural impacts. International Journal Man-Machine Studies, 38, 465 - 487

Ebert, D. D., Berking, M., Cuijpers, P., Lehr, D., Pörtner, M., \& Baumeister, H. (2015). Increasing the acceptance of internet-based mental health interventions in primary care patients with depressive sympotms. A randomized controlled trial. Journal of Affective Disorders 176 9-17 doi:10.1016/j.jad.2015.01.056

Eden, R., Burton-Jones, A., Scott, I., Staib, A., \& Sullivan, C. (2018). Effects of eHealth on hospital practice: synthesis of the current literature. Australian Health Review, 42, 568-578. doi:10.1071/AH17255

Fishbein, M., \& Ajzen, I. (1975). Belief, attitude, intention and behavior: An introduction to theory and research: Reading Mass: Addison Weisley Publishing Company.

Fleming, T., Bavin, L., Lucassen, M., Stasiak, K., Hopkins, S., \& Merry, S. (2018). Beyond the trial: Systematic review of real-world uptake and engagement with digital self-help interventions for depression, low mood, or anxiety. Journal of Medical Internet Research, 20, e199. doi:10.2196/jmir.9275

Hassounah, M., Raheel, H., \& Alhefzi, M. (2020). Digital response during the COVID-19 pandemic in Saudi Arabia. Journal of Medical Internet Research, 22, e19338. doi:10.2196/19338 
Isautier, J. M. J., Copp, T., Ayre, J., Cvejic, E., Meyerowitz-Katz, G., Batcup, C., ... McCaffery, K. J. (2020). People's expereinces and satisfaction with telehealth during the COVID-19 pandemic in Australia: Cross-sectional survey study. Journal of Medical Internet Research, 22, e24351. doi:10.2196/24531

Keasberry, J., Scott, I. A., Sullivan, C., Staib, A., \& Ashby, R. (2017). Going digital: a narritive overview of the clinical and organisational impacts of eHealth technologies in hospital practice. Australian Health Review, 41, 646-664. doi:10.1071/AHI6233

Lin, J., Faust, B., Ebert, D. D., Krämer, L., \& Baumeister, H. (2018). A web-based acceptance-facilitating intervention for identifying patients' acceptance, uptake and adherence of internet-and mobile-based pain interventions: randomized controlled trial. Journal of Medical Internet Research, 20, e244. doi:10.2196/jmir.9925

Linardon, J., Cuijpers, P., Carlbring, P., Messer, M., \& Fuller-Tyszkiwwicz, M. (2019). The efficacy of app-supported smartphone interventions for mental health problems: a meta-analysis of randomized controlled trials. World Psychiatry, 18, 325-336.

Liu, L., Cruz, A. M., Rincon, A. R., Buttar, V., Ranson, Q., \& Goertzen, D. (2015). What factors determine therapists' acceptance of new technologies for rehabilitation - a study using the Unified Theory of Acceptance and Use of Technology (UTAUT). Disability and Rehabilitation, 37, 447-455. doi:10.3109/09638288.2014.0923529

March, S., Day, J., Ritchie, G., Rowe, A., Gough, J., Hall, T., . . Ireland, M. (2018). Attitudes towards e-Mental health services in a community sample of adults: online survey. Journal of Medical Internet Research, 20 e59. doi:10.2196/jmir.9109

Mayer, G., Gronewold, N., Alvarea, S., Burns, B., Hilbel, T., \& Schultz, J. (2019). Acceptance and expectations of medical experts, students, and patients toward electronic mental health apps: cross-sectional quantitative and qualitative survey study. JMIR mental health, 6 e14018. doi:10.2196/14018

McEachan, R. R. C., Conner, M., Taylor, N. J., \& Lawton, R. J. (2011). Prospective prediction of health-related behaviours with the theory of planned behaviour: a meta-analysis. Health Psychology Review, 5, 97-144. doi:10.1080/17437199.2010.521684

Ministry of Health. (2016). New Zealand Health Strategy: Future direction. Retrieved from Wellington:

Oosterveen, E., Tzelepis, F., Ashton, L., \& Hutchesson, M. J. (2017). A systematic review of eHealth behavioral interventions targeting smoking, nutrition, alcohol, physical activity and/or obesity for young adults. Preventive Medicine, 99, 197-206. doi:10.1016/j.ypmed.2017.01.009

Parks, A. C., Williams, A. L., Kackloudis, G. M., Stafford, J. L., Boucher, E. M., \& Honomichl, R. D. (2020). The effects of a digital well-being intervention on patients with chronic conditions: observational study. Journal of Medical Internet Research, 22, e16211. doi:10.2196/16211

Patel, S., Akjtar, A., Malins, S., Wright, N., Rowley, E., Young, E., ... Morriss, R. (2020). The acceptability and usability of digital health interventions for adults with depression, anxiety, and somatoform disorders: qualitative systematic review and meta-synthesis. Journal of Medical Internet Research, 22, e16228. doi:10.2196/16228

Peine, A., Paffenholz, P., Martin, L., Dohmen, S., Matx, G., \& Loosen, S. H. (2020). Telemedicine in Germany during the COVID-19 pandemic: multi-professional national survey. Journal of Medical Internet Research, 22, e19745. doi:10.2196/19745

Proudfoot, J., Parker, G., Pavlovic, D. H., Manicavasagar, V., Adler, E., \& Whitton, A. (2010). Community attitudes to the appropriation of mobile phones for monitoring and managing depression, anxiety and stress Journal of Medical Internet Research, 12, e64. doi:10.2196/jmir.1475

Rosenstock, I. M., Strecher, V. J., \& Becker, M. H. (1988). Social learning theory and the health belief model. Health Education Quarterly, 15, 175-183

Schröder, J., Sautier, L., Kiriston, L., Berger, T., Meyer, B., Späth, C., ... Motritz, S. (2015). Development of a questionnaire measuing attitudes towards psychological online interventions-the APOI. Journal of Affective Disorders, 187, 136-141. doi:10.1016/j.jad.2015.08.044

Wangberg, S. C., Gammon, D., \& Spitznogle, K. (2007). In the eyes of the beholder: exploring psychologists' attitudes towards and use of e-therapy in Norway. Cyberpsychology and behavior, 10, 418-423. doi:10.1089/cpb.2006.9937 